\title{
LOW BENDING VIBRATIONS OF CRYSTALLINE WATER MOLECULES: AN ONGOING QUEST OR A FINAL WORD - TOPICAL REVIEW - A TRIBUTE TO ACADEMICIAN BOJAN ŠOPTRAJANOV-•
}

\author{
Ljupčo Pejov, Gligor Jovanovski \\ Institute of Chemistry, Faculty of Science, Ss. Cyril and Methodius University, \\ Skopje, Republic of Macedonia \\ Research Centre for Environment and Materials, Macedonian Academy of Sciences and Arts, \\ Skopje, Republic of Macedonia \\ e-mail: ljupcop@pmf.ukim.mk, gligor@pmf.ukim.mk
}

\begin{abstract}
The main aim of this topical review is to provide a concise but yet complete overview of the research that has been done in the field of low-lying crystalline water bending vibrations. Both theoretical and experimental work in the field is reviewed, and the most important dilemmas and obstacles hampering a direct explanation of the phenomenon are outlined. The present status in this field is also overviewed and clarified. While this topical review has mostly been focused on crystalline water molecules in crystalline hydrates and their vibrational properties, also some other interesting and exciting systems that have recently attracted the attention of the scientific community are covered. These included water absorbed on surfaces as well as water at the air-water interfaces.
\end{abstract}

Key words: crystalline water; crystalline hydrates; water bending vibrations; IR spectroscopy; quantum theory

\section{INTRODUCTION}

Water is, beyond any doubt, one of the most ubiquitous and at the same time one of the most widely studied substances across numerous scientific areas. It is perhaps impossible to overestimate its relevance to the very existence of life in the form that we know of. As a consequence of this, and also accounting for the fact that processes essential to life take place within the cells and subcellular fragments of the living organisms, to refer to the water confined within such micro- or nanosized spaces, the term "biological water" has been coined and, aside from its perhaps pretentious character, widely used in the literature [1-3 and references therein]. Properties of biological water could be rather different from the properties manifested by this substance when it appears in bulk form. In several hot-topic recent studies, the dynamics of water motions inside confining molecular cage-like systems (such as, e.g., $\mathrm{C}_{60}$ ) has been thoroughly studied from both theoretical and experimental sides [4-9 and references therein]. Aside from all these cutting-edge research topics related to water embedded in small, nanosized systems, water is still an unresolved mystery even in its "conventional", i.e. bulk form, of appearance. The dynamics of hydrogen bond forming and breaking within liquid water is a subject of continual research interests. Behavior of the essential products of water autoprotolysis process, the $\mathrm{H}_{3} \mathrm{O}^{+}$and $\mathrm{OH}^{-}$ionic species, has also been a subject of continuing debates in the literature [10-17]. Even very essential issues, such as the ability of the $\mathrm{OH}^{-}$ions to act as hydrogenbond proton donors in bulk water, have been addressed from various viewpoints [10-17].

Aside from its relevance to biological systems, water is widely present in inorganic systems as well. It actually incorporates into the crystalline lattices of numerous inorganic compounds, (involv- 
ing minerals and their synthetic analogues), as crystalline water. Compounds containing crystalline water are known as crystalline hydrates [18, 19]. Investigations of the static and dynamical properties of such crystalline water can lead to a number of important information about crystalline surrounding and the dynamics of crystalline lattices in general. In the course of these investigations, numerous experimental techniques have been employed, among which, vibrational spectroscopy (both infrared and Raman) and diffraction techniques have been of particular interest. This review focuses on the former. However, especially in the course of both hardware and theoretical methodology developments, contemporary theoretical analysis of the experimentally observed spectral features has become a necessity in serious scientific publications, in certain cases shedding substantially more light on the issues in question. The most widely used vibrational spectroscopic techniques measure the energy differences between certain vibrational levels of complex molecular and solid state systems in the form of bands appearing in the absorption/transmission spectra. The surrounding in complex environments affects these energy differences in a rather complex manner and the overall effect enables one to use the molecular systems as a sort of probe to characterize the complex environment in which the molecule is embedded. In the course of studies related to these aspects, the $\mathrm{O}-\mathrm{H}$ stretching vibrations of crystalline water molecules (as well as of hydronium and hydroxide ions) have been widely used as a very indicator of the existence of e.g. a hydrogen bonding or some other noncovalent interaction within the medium, involving the water molecule (or the corresponding ion) in question [20 and references therein]. This possibility has been much exploited using the advantage of the so-called isotopic isolation techniques. These techniques employ exchange of a rather small (or, on the other extreme, rather large) portion of the hydrogen atoms with deuterium ones, usually by a process of simple recrystallization from mixture of $\mathrm{H}_{2} \mathrm{O}$ and $\mathrm{D}_{2} \mathrm{O}$. When only a small portion of hydrogen atoms is replaced by deuterium ones within the crystal (or other complex environment) one encounters a very small portion of HDO molecules within a vast majority of $\mathrm{H}_{2} \mathrm{O}$ ones. In the opposite extreme, one encounters a very small portion of $\mathrm{HDO}$ molecules within a vast majority of $\mathrm{D}_{2} \mathrm{O}$ ones. Within the HDO molecules, which are practically isolated among the other isotopomers, the intramolecular $\mathrm{O}-\mathrm{H}$ and $\mathrm{O}-\mathrm{D}$ oscillators are completely decoupled, due to the mass difference between hydrogen and deuterium. At the same time, intermolecular couplings between identical oscillators are eliminated as well, so that a rather clear spectral picture can be seen, within which numerous structural features can be elucidated, even such as the number of distinct $\mathrm{O}-\mathrm{H}(\mathrm{D})$ oscillators within the crystal (or other medium), the nature and strength of the interactions involving a particular $\mathrm{O}-\mathrm{H}(\mathrm{D})$ oscillator in question. For example, the involvement of an $\mathrm{O}-\mathrm{H}(\mathrm{D})$ oscillator in an intra- or intermolecular hydrogen bond has been often judged by the direction of the shift in the $\mathrm{O}-\mathrm{H}(\mathrm{D})$ stretching frequency. The magnitude of this shift, on the other hand, has often been found to be proportional to the interaction strength [10-17, 20]. Besides the effect of noncovalent interactions on the static and dynamical properties of the intramolecular O-H(D) oscillators, also the influence of incrystal (or external) electrostatic fields on the statics and dynamics of the O-H(D) oscillators has been thoroughly addressed [21-24]. It has been actually shown that in certain cases (such as, e.g., in case of the $\mathrm{O}-\mathrm{H}^{-}$ions placed within certain crystalline environments), in some cases the electric fields may dictate even the direction of the shift of the O-H(D) stretching vibrational frequencies [20]. Therefore, in such cases, observation of a blue- or red-shift of a given stretching mode can not be a priori attributed to the existence (or non-existence) a noncovalent intermolecular interaction (e.g. of a hydrogen bonding type) [20]. Due to all these reasons, $\mathrm{O}-\mathrm{H}(\mathrm{D})$ stretching vibrations in crystalline water molecules have been studied a lot, and numerous spectra-structure correlations have even been established in the literature [e.g. 25-28].

Contrary to what has been previously concisely outlined about the water stretching vibrations, water bending vibrations have been studied much less. The $\delta(\mathrm{HOH})$ motion (or "scissoring" motion) of crystalline water molecules has often been thought of as being rather insensitive to the crystalline (or other) environments [29-31]. Such viewpoint has been supported by the early theoretical studies of water molecule dynamics as influenced by cationic and anionic species [32-36]. The bending vibrational motion of free water molecule gives rise to a band appearing at $1594.6 \mathrm{~cm}^{-1}$ [30, $31]$. It has been long thought that in crystalline water molecules, the frequency of this mode is blueshifted (i.e. shifted to higher frequencies) with respect to the gas phase value. Such belief was supported by the most of the available theoretical predictions based mainly on classical vibrational dynamics simulations, but also on $a b$ initio calculations [32-36]. Concisely, theoretical calculations indicated that in the usually encountered structural 
patterns in solid state the water bending frequency should not be much affected by the presence of cations in the neighborhood of vibrating water. At the same time, presence of anionic species was expected to enlarge the $\mathrm{HOH}$ bending force constants, and the overall effect would be frequency blueshift. Both effects were, however, expected to be small, and the resulting overall perturbation of the energy difference between the ground and the first excited $\delta(\mathrm{HOH})$ levels would be of the order of just a few percents of the gas-phase value. More involved computations, including additional force constants due to both coordination and involvement in hydrogen bonding, have also shown that a frequency upshift is expected upon inclusion of an additional force constant in the vibrational force field of crystalline water [32-36]. All these theoretical findings actually correspond to the situation that has most frequently been encountered in practice.

However, in-depth spectroscopic and structural studies of a series of compounds of the type $\mathrm{MKPO}_{4} \cdot \mathrm{H}_{2} \mathrm{O}$, though at first sight inconsistent with the established opinion concerning these matters, have substantially changed the situation and opinion in the field [37-45]. The main aim of this review paper is to point out the development of scientific thought related to the problem of water bending vibrations appearing at significantly lower frequencies than the gas phase values. Academician Soptrajanov has invaluable contribution to this field, and therefore with great pleasure we dedicate this topical review to him, on the occasion of his $80^{\text {th }}$ birthday.

\section{EXPERIMENTAL TECHNIQUES}

Essentially all of the experimental literature data referred to in the present paper have been obtained with infrared spectroscopic techniques. In references [41-45], Fourier-transform infrared spectra have been recorded on a Perkin-Elmer System 2000 FT-IR interferometer. Spectra have been collected at both room temperature as well as at liquid nitrogen boiling temperature (actually, at about $-174{ }^{\circ} \mathrm{C}$ ), using a Graseby-Specac variable temperature cell coupled with a controller. To achieve a good signal-to-noise ratio, often at least 32 spectra have been collected and averaged (or even more in certain cases, when required - in some cases even up to 128). Further processing of the spectra in the sense of determination of band maxima position, half-widths and general band shapes has been done with Grams32 program package [46]. For this purpose, usually standard nonlinear curve fitting procedures were implemented, using either linear combinations of Gaussian and Lorentzian model band shape functions, or Voigt model functions.

\section{A SURVEY OF EXPERIMENTAL FINDINGS}

In this context, we will overview the experimental spectroscopic proofs for the appearance of bands demonstrating significantly red-shifted water bending (scissoring) vibrations in certain crystalline hydrates, as well as for water molecules adsorbed on some surfaces. In cases when structural data are known as well, we will discuss the local geometric specificities related to the in-crystalline water molecules that could be a possible source for the observed peculiar (or, at least, unusual) vibrational behavior.

The first notification concerning the existence of IR spectral bands due to water bending motions is present in the paper by Falk [28]. However, the lower frequency limit for this mode noted in the mentioned paper $\left(1582 \mathrm{~cm}^{-1}\right)$ is only slightly below the gas phase value. Though such slight red-shifts were related to the presence of metal cationic species with smaller radii possessing higher charge in the crystal structure of the studied compounds (and therefore it was implied that electrostatics has to be intrinsically related to this observation), the situation was not clarified in detail.

Very recently, as a matter of fact, another interesting example of water exhibiting low bending vibrations has been presented in the literature. It refers to water adsorbed on $\mathrm{TiO}_{2}$ surface [47]. Experimental studies of water adsorption on titanium dioxide surface are rather important in the context of materials chemistry and physics in general as well as in surface science. Experimental IR spectroscopic data (as described and cited in Ref. [47]) have unequivocally shown that a defined band (appearing as a shoulder in the IR spectral patterns) at $\sim 1560 \mathrm{~cm}^{-1}$ could be attributed to water $v_{2}(\delta(\mathrm{H}-$ $\mathrm{O}-\mathrm{H})$ ) mode, strongly red-shifted by about $85 \mathrm{~cm}^{-1}$ as compared to the liquid water bending appearing at $1645 \mathrm{~cm}^{-1}$. In [47], such assignment was supported by DFT study of finite-clusters mimicking the adsorption of water molecules on nanocrystalline $\mathrm{TiO}_{2}$. The authors have found out that the redshift of water bending mode does not correlate with the Mulliken charges of the surface exposed Ticationic sites, but such a correlation seems to exist with the natural bond orbital (NBO) charges. This is in a sense expected, if one keeps in mind the lack of exact physical significance of the Mulliken charges. Though widely used in the literature, the 
Mulliken charge partitioning scheme was actually never intended to be used for atomic charge assignments, but rather for other purposes. This point has been discussed in numerous studies by our and other groups [48, 49 and references therein]. We have even clearly demonstrated the rather counterintuitive results that could be brought about by straightforward usage of "Mulliken charges" [48, 49]. Atomic charges derived on the basis of natural bond orbital theory by Weinhold and Carpenter [50 and references therein] have certainly much clearer physical meaning, although one has to keep in mind that since the only exact physical observable is the electronic density itself, no scheme for its partitioning into "atomic charges" should be regarded as unambiguous. However, NBO charges obviously necessarily describe better the electrostatic field generated by the surface exposed titanium ionic centers and the effects that this field exerts on the water bending frequencies. Note, however, that the mentioned correlation even in the case of NBO charges has been found only in the case of simultaneous absorption of five water molecules. No such correlation has been found to exist in the case of absorption of a single water molecule on the titanium dioxide surface. Such findings, though certainly emphasizing the significance of electrostatics for the discussed phenomenon, also strongly imply a rather complex, cooperative nature of the overall water bending frequency shifts induced by surface absorption or by inclusion of water molecules into crystalline hydrates.

In a series of papers coauthored by the members of the group around academician Šptrajanov, numerous examples of the appearance of rather significantly red-shifted water bending vibrations in crystalline hydrates have been presented [37-45]. In the first paper more widely circulated paper of a series devoted to this phenomenon [41], Šoptrajanov has briefly reviewed the awareness concerning the very existence of "low water bending modes", and he has also referred to two particular examples of compounds (crystalline hydrates) in which crystalline water molecules exhibit such pronounced red shift of the water bending mode. The two particular examples considered were two members of the series of compounds with a general formula $\mathrm{MKPO}_{4} \cdot \mathrm{H}_{2} \mathrm{O}$, where $\mathrm{M} \in\{\mathrm{Ni}, \mathrm{Mg}\}$. In the case of $\mathrm{NiKPO}_{4} \cdot \mathrm{H}_{2} \mathrm{O}$ the band due to water bending mode was found to appear at $1478 \mathrm{~cm}^{-1}$, while in the case of $\mathrm{MgKPO}_{4} \cdot \mathrm{H}_{2} \mathrm{O}$, the corresponding frequency is $1470 \mathrm{~cm}^{-1}$. It is worth noting at this point that the phenomenon of low water bending in crystalline hydrates has actually been discovered much earlier by Šoptrajanov and collaborators [37-40], but the first studies devoted to its presentation and clarification had not been more widely circulated. Therefore, reference [41] may be regarded as a first attempt to bring the awareness of the red shift of crystalline water bending modes to a wider audience. In [41], the assignment of the $1478 \mathrm{~cm}^{-1}$ band in the case of $\mathrm{NiKPO}_{4} \cdot \mathrm{H}_{2} \mathrm{O}$ to the crystalline water bending vibration was based on a detailed and thorough spectroscopic study of a series of protiated and partially deuterated samples at both room temperature and at liquid nitrogen boiling temperature. The spectral region from $1900-1300 \mathrm{~cm}^{-1}$ in the case of $\mathrm{NiKPO}_{4} \cdot \mathrm{H}_{2} \mathrm{O}$ is obviously dominated by a single band of appreciable IR intensity (Fig.1. in Ref. [41]) which is directly attributable to fundamental vibrational transition. Subsequent studies of partially deuterated analogues of this compound have been undertaken in order to confirm that it is indeed a crystalline hydrate. This has been demonstrated by following the evolution of the relevant spectral bands upon partial deuteration of the parent compound. Concerning the previously mentioned $1900-1300 \mathrm{~cm}^{-1}$ region, it has been unequivocally demonstrated that the band appearing in this area in the case of protiated compound completely disappear upon complete deuteration. Actually, in the spectra of partially deuterated analogue with low deuterium content, a new band has been shown to appear at $1315 \mathrm{~cm}^{-1}$ which initially gains in intensity upon deuterium content increase (at up to $50 \%$ D), but further gradually disappears and is completely absent in the spectra of fully deuterated sample. This, in conjunction with the behavior of the region of the $\mathrm{HOH}, \mathrm{HOD}$ and DOD stretching bands, has been used as a strong argument confirming that one deals with crystalline hydrates and further confirming the initial empirical assignment of the $\delta(\mathrm{HOH})$ band at $1478 \mathrm{~cm}^{-1}$. Other spectral features in the case of protiated and deuterated sample of this compound have further implied that the $\mathrm{HOH}$ angle is probably close to $90^{\circ}$, which could have significant implications in relation to appearance of the $\mathrm{HOH}$ bending mode at rather low frequencies. Unfortunately, this implication could not be confirmed by X-ray structural investigations, as the positions of hydrogen atoms could not be determined.

In subsequent combined experimental and theoretical studies [42, 43], Šoptrajanov, Jovanovski and Pejov have focused on two further members of the series of compounds of the type $\mathrm{MKPO}_{4} \cdot \mathrm{H}_{2} \mathrm{O}$, those in which $\mathrm{M} \in\{\mathrm{Co}, \mathrm{Mn}\}$. In this study, both RT and LNT spectra of protiated and partially, as well as practically fully, deuterated samples of the mentioned compounds have been recorded and analyzed in detail. In the case of Co 
compound, no band of appreciable intensity has been found to appear in the region where bands due to the $\delta(\mathrm{HOH})$ mode are expected (above $1600 \mathrm{~cm}^{-1}$ ). Instead, a rather intensive band has been found to appear at $1464 \mathrm{~cm}^{-1}$ in the LNT FT IR spectrum. Analogously as in the case of $\mathrm{MKPO}_{4} \cdot \mathrm{H}_{2} \mathrm{O}$, however, two much weaker satellite bands have been found to appear at 1708 and $1614 \mathrm{~cm}^{-1}$. All of the mentioned bands (the intense one and the two satellite) were found to be deuteration-sensitve and are completely absent in the spectra of fully deuterated analogue. This has been taken as an unequivocal proof of the relation of these bands to the crystalline water vibrational motions. However, only the most intensive band could be attributed to fundamental (first order, i.e. $|0>\rightarrow| 1>$ ) vibrational mode. It is exactly this band that the authors have attributed to the $\delta(\mathrm{HOH})$ mode. The satellite bands have, on the other hand, been attributed to the second-order vibrational transitions involving lowerfrequency fundamentals. One such candidate that the authors have pointed at is the band at $828 \mathrm{~cm}^{-1}$ originating from water librations. On the basis of the results of the factor-group analysis, this mode has actually been found to posses the right symmetry $\left(A_{1}\right)$ to interact with a component of the $\delta(\mathrm{HOH})|0>\rightarrow| 1>$ fundamental transition. Comparison between the estimated and observed overtone frequency in this case have, however, indicated a rather weak anharmonic vibrational coupling. The situation with the crystalline water vibrations in the case of $\mathrm{MnKPO}_{4} \cdot \mathrm{H}_{2} \mathrm{O}$ has been found to be rather different than in the cobalt counterpart. In the context of the current review, we will focus on the spectral region of the $\delta(\mathrm{HOH})$ fundamental modes. In this region, now two bands with almost equal IR intensities have been found to appear, at 1661 and $1433 \mathrm{~cm}^{-1}$; these are accompanied with a much weaker band positioned at $1525 \mathrm{~cm}^{-1}$. All these bands have been found to be notably sensitive to deuteration and they completely disappear upon complete deuteration. Comparing the regions of appearance of bands due to $\delta(\mathrm{HOH})$ fundamental modes as well as the regions of appearance of water rocking librational modes in the series of $\mathrm{MKPO}_{4} \cdot \mathrm{H}_{2} \mathrm{O}$-type compounds, where $\mathrm{M}$ is $\mathrm{Ni}$, Co and $\mathrm{Mn}$, the authors of [43] have concluded that the frequency of water librational band follows the order $\mathrm{Mn}<\mathrm{Co}<\mathrm{Ni}$. At the same time, the authors have noticed that the closer the position of the direct overtone of this rocking mode $\left(\rho\left(\mathrm{H}_{2} \mathrm{O}\right) \mid 0>\rightarrow\right.$ |2> vibrational transition) is to the position of the strongest band in the $\delta(\mathrm{HOH})$ region, the closer the intensities of the bands in this region become. On the basis of these experimental observations, the authors of reference [43] have concluded that actually nearly-accidental degeneracy of vibrational modes takes place, involving the fundamental $\delta(\mathrm{HOH})$ and overtone $\rho\left(\mathrm{H}_{2} \mathrm{O}\right)$. As the conditions for Fermi-like resonance become fulfilled, intensity redistribution between the $\delta(\mathrm{HOH})$ fundamental and $\rho\left(\mathrm{H}_{2} \mathrm{O}\right)$ overtone bands occurs, the later gaining in intensity as compared to the case in which no vibrational coupling takes place. Further indication of such vibrational mode mixing was the additional shift of the $\delta(\mathrm{HOH})$ fundamental mode to lower frequencies in the case of $\mathrm{MnKPO}_{4} \cdot \mathrm{H}_{2} \mathrm{O}$ as compared to the $\mathrm{Co}$ and $\mathrm{Ni}$ counterparts. This is attributed to the mutual repelling of the interacting vibrational levels $(\delta(\mathrm{HOH})$ first excited vibrational state $\mid 1>$ and $\rho\left(\mathrm{H}_{2} \mathrm{O}\right)$ second excited vibrational level $\left.|2\rangle\right)$. This is schematically presented in Figure 1.

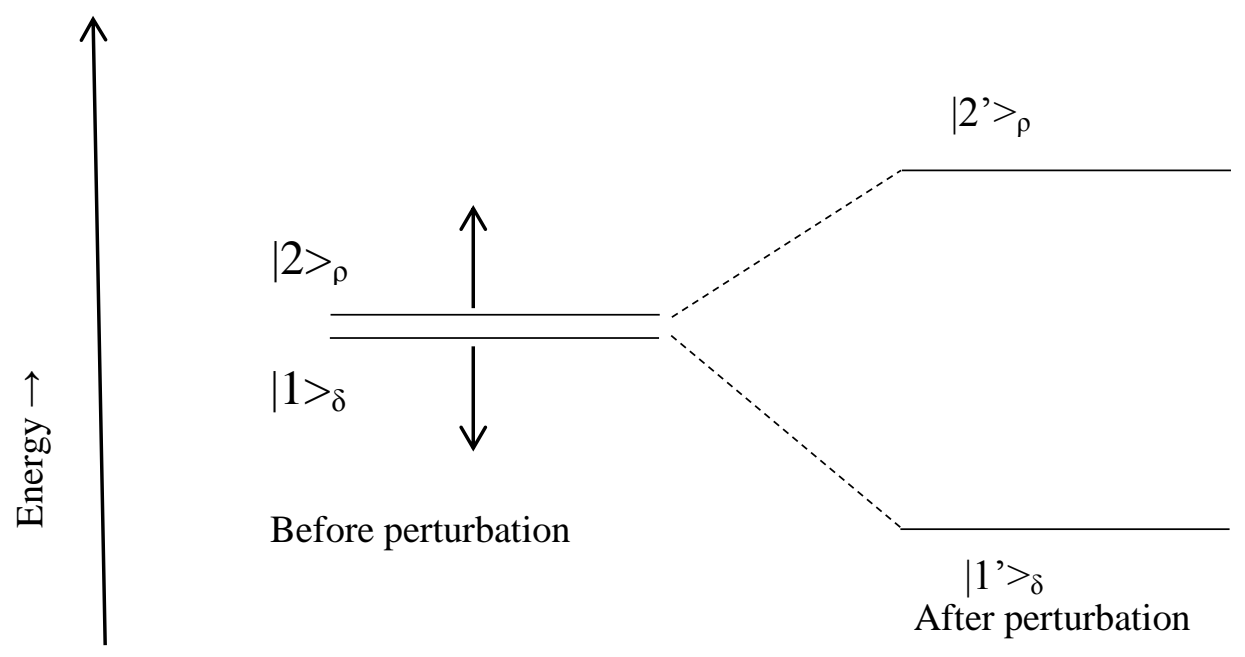

Figure 1. A schematic presentation of the mutual repelling of the interacting vibrational levels $(\delta(\mathrm{HOH})$ first excited vibrational state $\mid 1>$ and $\rho\left(\mathrm{H}_{2} \mathrm{O}\right)$ second excited vibrational level $\left.\mid 2>\right)$ due to vibrational mode mixing

as a consequence of accidental near-degeneracy. 
Further work by Šoptrajanov and collaborators [44] in the field has been devoted to a series of ammonium phosphate compounds with general formula $\mathrm{MNH}_{4} \mathrm{PO}_{4} \cdot \mathrm{H}_{2} \mathrm{O}$ (where $\mathrm{M} \in\{\mathrm{Mg}, \mathrm{Co}, \mathrm{Ni}$, $\mathrm{Mn}, \mathrm{Cd}\}$ ) which have been found to be isomorphous to the potassium analogues $\mathrm{MKPO}_{4} \cdot \mathrm{H}_{2} \mathrm{O}$. Although the spectra in this series of compounds appeared to be much more complicated with respect to assignment of vibrational modes due to crystalline water, as a consequence of the presence of ammonium ions, the careful and thorough analysis of the experimental spectra at RT and LNT of the protiated as well as of a series of deuterated analogues of $\mathrm{MgNH}_{4} \mathrm{PO}_{4} \cdot \mathrm{H}_{2} \mathrm{O}$ (the synthetic analogue of mineral dittmarite) carried out by the authors, have led them to rather significant conclusions and thorough reassignments of bands in this case. It is worth noting that besides their fundamental significance, the compounds of the mentioned series contain ammonium ions involved in strong intermolecular interactions of hydrogen bond type within the crystal, and are therefore of certain applicative importance, as potential proton conductors. The bands that are in the focus of the present review (due to the water bending fundamentals) fall in the same spectral region as the bands due to the two of the $\mathrm{NH}_{4}{ }^{+}$ion bending modes (usually denoted as $v_{2}$ and $v_{4}$ ). All these bands are, of course, expected to be deuteration-sensitive. Indeed, the authors of [44] have found several intensive, deuteration-sensitive bands in the spectral region from 1700 to $1400 \mathrm{~cm}^{-1}$ in the FT IR spectra of $\mathrm{MgNH}_{4} \mathrm{PO}_{4} \cdot \mathrm{H}_{2} \mathrm{O}$. Due to the bands originating from ammonium cations, an exact and unequivocal assignment of bands due to water bending fundamentals in this region would most probably be hampered, if there was not a strong evidence for the isomorphism between the currently studied compound and its potassium counterpart. Careful inspection of spectra of both samples enabled the authors to precisely locate the position of $\delta(\mathrm{HOH}) \mid 0>$ $\rightarrow \mid 1>$ fundamental band and to make substantial revision of the assignments of bands offered in an earlier study [51], most of which are directly related to the appearance of the fundamental $\delta(\mathrm{HOH})$ band at frequencies significantly lower than the gas phase value. In the $\delta(\mathrm{HOH})$ (and $\delta\left(\mathrm{NH}_{4}\right)$ ) spectral region at LNT, as many as five bands appear at $1663,1536,1482,1432$ and $1472 \mathrm{~cm}^{-1}$ (the last one being of lowest intensity, i.e. appearing as a shoulder). Closer inspection of the evolution of appearance of this region upon deuteration has revealed that the band at $1316 \mathrm{~cm}^{-1}$ appearing in the spectra of slightly deuterated analogue of $\mathrm{MgNH}_{4} \mathrm{PO}_{4} \cdot \mathrm{H}_{2} \mathrm{O}$ most probably originates from the $\delta(\mathrm{HOD})$ mode.
The authors have, however, found it rather hard to clarify completely the spectral picture upon further increase of the deuterium content due to the formation of various species of partly deuterated ammonium ionic species [44]. It is worth noting that the situation here actually suffers from an additional complication related to the possible Fermi resonance between $v_{4}$ mode of ammonium species and $v_{2}$ of crystalline water. Two components of the former vibrational modes are, under the site-group approximation, of the same symmetry as the water bending mode and therefore appreciable vibrational mode mixing could take place. The authors have, however, in this context also provided a further indirect proof that the $\mathrm{HOH}$ bending mode gives rise to a band at appreciably lower frequency than the gas phase value. This proof has been based on the observed trend in the series of $\mathrm{MNH}_{4} \mathrm{PO}_{4} \cdot \mathrm{H}_{2} \mathrm{O}$ type compounds upon change of the $\mathrm{M}$ cationic species. Namely, the mentioned shift on going from $\mathrm{Ni}$ to $\mathrm{Mn}$ has been found to closely resemble the situation encountered in the series of (presumably isomorphous) series of $\mathrm{MKPO}_{4} \cdot \mathrm{H}_{2} \mathrm{O}$ - type compounds.

Although mentioned in the final segment of this part devoted to experimental evidence related to appearance of low-lying bands due to crystalline water bending modes, the aspect that we will address now appeared to be a key one for thorough understanding of the spectroscopic data. Aside from enabling the researchers to apply group theoretical formalism and therefore to make definite conclusions concerning e.g. vibrational couplings between the modes, as well as the very appearance of bands due to particular modes, the insight into the in-crystalline environment around the "peculiar" crystalline water molecules have also enabled further theoretical insights into the reasons behind unusual spectral features to be gained. The aspect in question is the experimental determination of the structure of $\mathrm{MgKPO}_{4} \cdot \mathrm{H}_{2} \mathrm{O}$ by single-crystal X-ray diffraction technique. In [52], Jovanovski, Pocev and Kaitner have determined the crystal structure of this prototypical compound of the series $\mathrm{MKPO}_{4} \cdot \mathrm{H}_{2} \mathrm{O}$. This has been done by the singlecrystal X-ray diffraction technique, at room temperature, using 246 independent reflections for the structure determination. Refinement of coordinates of all non-hydrogen atoms has been done up to final $R=0.064$. The compound has been found to crystallize in the orthorhombic space group $P m n 2_{1}$, with $Z=2$. The structure of this molecular crystal is composed by $\mathrm{PO}_{4}$ tetrahedral species, $\mathrm{K}$ and $\mathrm{Mg}$ ions, as well as $\mathrm{H}_{2} \mathrm{O}$ molecules. $\mathrm{Mg}$ ions are coordinated to as many as 5 oxygen atoms belonging to 
phosphate groups and one crystalline water oxygen atom. The potassium ion is, on the other hand, surrounded by as many as eight oxygen atoms (both from water molecules and phosphate groups). Perhaps the most important structural feature (at least in the context of low water bending modes) is the fact that water molecules were found to form bifur- cated hydrogen bonds. However, the exact hydrogen bonding pattern was difficult to establish with a high degree of certainty, as the hydrogen atom positions in the structure have not been determined. Crystalline water molecules are surrounded by four phosphate ion oxygen atoms and by single $\mathrm{Mg}$ and single $\mathrm{K}$ ions.

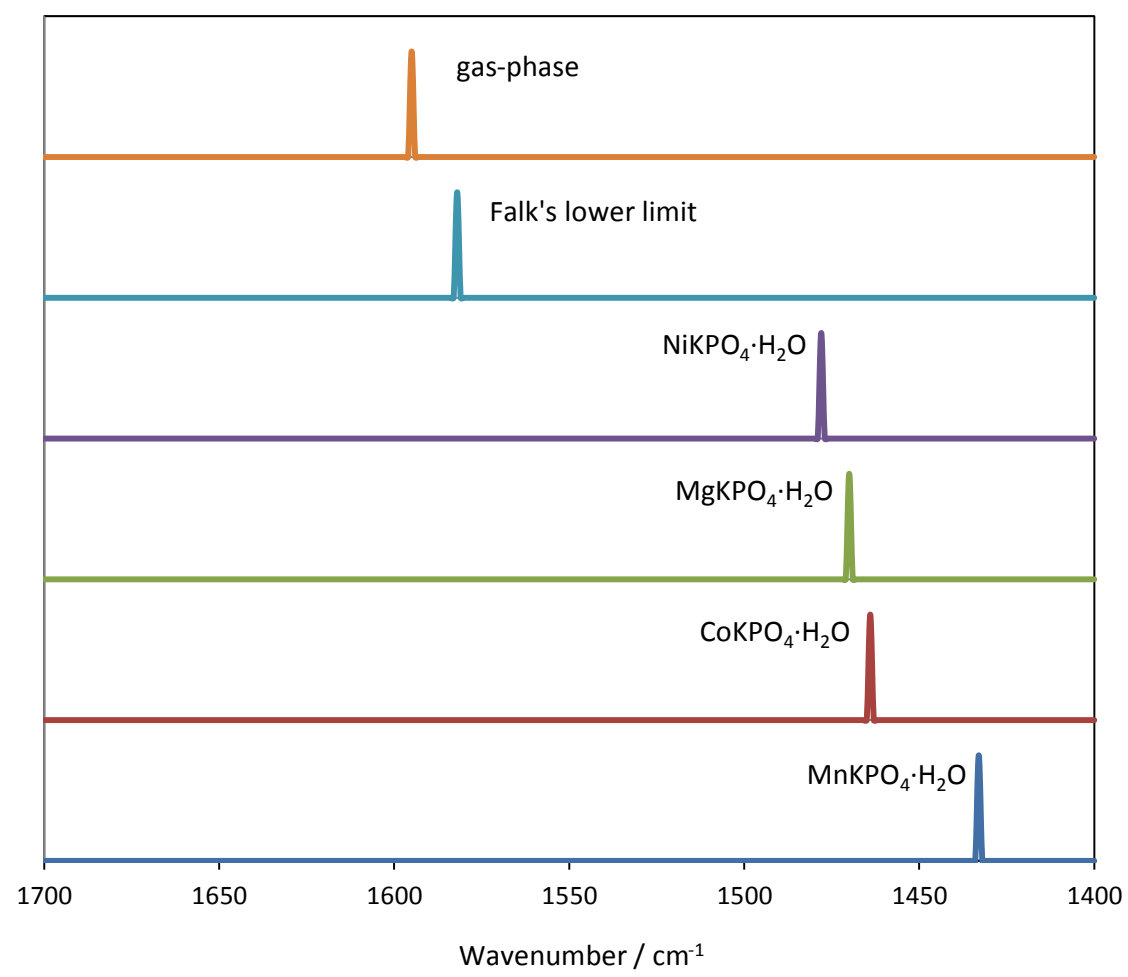

Figure 2. A schematic presentation of the positions of $\delta(\mathrm{HOH})$ bands in the IR spectra of the mentioned compounds, compared with the position of the $\delta(\mathrm{HOH})$ band in the case of gaseous water and the "Falk's lower limit".

To summarize in a pictorial way the previously outlined survey of experimental data related to the title issue, in Figure 2 we have schematically presented the positions of $\delta(\mathrm{HOH})$ bands in the IR spectra of the mentioned compounds, compared with the position of the $\delta(\mathrm{HOH})$ band in the case of gaseous water.

As an unambiguous conclusion, aside from the discussed peculiarities and intricacies of band assignments which seem to be a necessity in the case of the studied series of compounds, it can be stated that the bands due to crystalline water $\mathrm{HOH}$ bending (scissoring) modes in all of these cases appear at significantly lower frequencies that the Falk's low limit. This is a rather uncommon situation and such observations impose a quest towards a more in-depth insight into the reasons responsible for such notable red-shifts of the water bending modes in particular solid-state environments. Theoretical modeling tools seem to be invaluable in this context.

\section{CHOSEN SYSTEMS AND GENERAL METHODOLOGY ASPECTS}

A wide variety of theoretical/computational approaches has been applied to approach the problem dealt with in this topical review, i.e. the problem of low-lying bending vibrations. The main aim of essentially all theoretical studies was to get an in-depth insight into the physical reasons behind the observed vibrational frequency red-shifts, and, at the same time, to become aware of the particular segment/fragment of the environment (e.g. incrystal) that induces such red-shift. The simplest approaches involved semiempirical methods e.g. with PM3 Hamiltonian, as used in Refs. [41, 42], Hartree-Fock method [41, 42], and Density functional theory (DFT) approaches [43-45] using various combinations of exchange and correlation functionals. Various basis sets have been used for or- 
bital expansion in the course of solving the HF or Kohn-Sham equations in an iterative manner, ranging from the rather popular LANL2DZ, which is a combination of D95 on first row elements and Los Alamos effective core potential (ECP) plus DZ on $\mathrm{Na}-\mathrm{Bi}[53,54]$, up to the rather flexible, Pople-type $6-311++\mathrm{G}(3 d f, 3 p d)$ basis of triple-zeta quality. In the studies performed within our group, in the course of all DFT computations, special attention has been paid to the SCF convergence-related issues. Thus, in all our studies relying on the DFT approach, the Kohn-Sham (KS) SCF equations were solved iteratively for each particular purpose of this study, with an "ultrafine" $(99,590)$ grid for numerical integration (99 radial and 590 angular integration points). In the case of free water molecule, we have located the stationary points on the potential energy surface (PES) employing Schlegel's gradient optimization algorithm [55], that relies on analytical computation of the energy derivatives with respect to nuclear coordinates. The character of the stationary points located on the corresponding PES was further tested by subsequent computation and analysis of the Hessian matrices. The absence of negative eigenvalues of the secondderivative matrix indicated the true minimum character of the particular stationary point on the PES.

In cases when geometry and vibrational spectroscopic properties of water molecule embedded in a fragment (cluster) mimicking the actual crystalline environment in the studied class of compounds were explored, only the intra- and intermolecular geometry parameters related to crystalline water were allowed to relax (i.e. partial geometry optimizations were carried out), while keeping all other parameters within the cluster fixed at their experimental values.

To simulate the influence of purely electrostatic contributions to the changes in geometry and vibrational frequencies, also finite-field calculations were carried out by our group [42, 43, 45]. Sequentially, electrostatic fields with various strengths (ranging from 0.020 to 0.060 a.u.) were applied along $x, y$ and $z$ axes of a local coordinate system fixed to water molecule (Fig. 3) and the changes in electron density distributions and other molecular parameters relevant to the presently studied phenomenon were monitored. This was done by explicit inclusion of the electrostatic field $\vec{F}$ in the many-particle Hamiltonian, i.e. by iteratively solving the Schrödinger equation:

$$
[\hat{H}+\vec{F} \cdot \vec{r}] \Psi=E \Psi
$$

in an SCF manner.

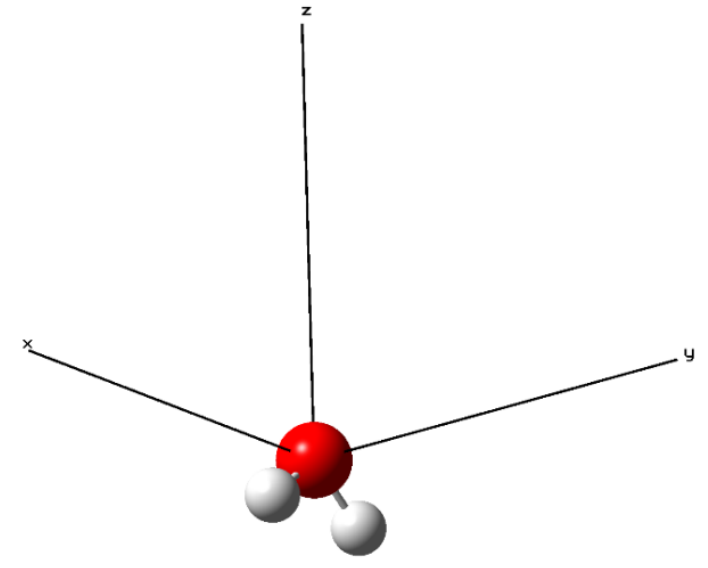

Figure 3. Orientation of the local coordinate system fixed to water molecule used in the computations.

For a more in-depth and in a sense more pictorial and chemically intuitive description of the fundamental bonding features encountered in the studied cases, both Weinhold's Natural bond orbital (NBO) analyses [50] and Bader's atoms in molecules (AIM) approaches were implemented to analyze the electronic density, in particular in the noncovalent bonding region (characterized with low density values and, at the same time, high gradient) [56].

All quantum chemical calculations were carried out by GAUSSIAN 03 series of computer codes [57].

\section{INFERENCES FROM THEORETICAL CALCULATIONS}

In our early theoretical studies devoted to possible clarifications of the reasons behind the appearance of pronouncedly low $\mathrm{HOH}$ bending frequencies in crystalline hydrates we have applied an exact approach to compute those values [41-43]. We have, namely, scanned the one-dimensional cut through the complete vibrational potential energy hypersurface of free and in-crystal water molecule corresponding to the $\delta(\mathrm{HOH})$ motion. This has been done by a series of pointwise energy calculations, varying the $\mathrm{HOH}$ angle with a step of $2^{\circ}$. The resulting function $V=f(\alpha)$ was subsequently fitted to a fourth - order polynomial in $\Delta \alpha(\Delta \alpha=\alpha$ $-\alpha_{\mathrm{e}}, \alpha_{\mathrm{e}}$ being the equilibrium value of $\alpha$ ) of the form:

$$
\begin{aligned}
& V(\Delta \alpha)=V_{0}+\frac{1}{2} k_{\alpha \alpha} r_{\mathrm{OH}, \mathrm{e}}^{2}(\Delta \alpha)^{2}+k_{\alpha \alpha \alpha} r_{\mathrm{OH}, \mathrm{e}}^{3}(\Delta \alpha)^{3}+ \\
& +k_{\alpha \alpha \alpha \alpha} r_{\mathrm{OH}, \mathrm{e}}^{4}(\Delta \alpha)^{4}
\end{aligned}
$$


The resulting Schrödinger equation has subsequently been solved with the second-order perturbation theoretical (SOPT) approach. It has been actually shown that the SOPT leads to values of the $\mid 0>\rightarrow$ |1> transition energies that are rather close to those obtained e.g. by the linear variational technique in cases with small anharmonic corrections (as is the presently studied case). To model the in-crystal water molecule, two approaches have been adopted in our initial study [41, 42]. Within the first one, the in-crystal water molecule was embedded in an environment composed by only the nearest neighbors within the crystal, while in the second one, the water molecule has been immersed in a homogeneous electrostatic field with different orientations. These initial studies have been, however, based on the semiempirical PM3 Hamiltonian and, in parallel, on the $a b$ initio Hartree-Fock theory (HF), using either the rather large, triple-zeta quality $6-311++\mathrm{G}$ $(3 d f, 3 p d)$ basis set for orbital expansion, or the LANL2DZ basis. Although these initial attempts to model the title phenomenon have led to excellent agreement of the free water anharmonic $\mathrm{HOH}$ bending frequency computed at $\mathrm{HF} / 6-311++\mathrm{G}$ $(3 d f, 3 p d)$ level of theory with the experimental one (1605.6 vs. $1594.6 \mathrm{~cm}^{-1}$ ), the computed in-crystal values with explicitly included nearest neighbors have been found to be higher than the free-water values, which is contrary to the experimental findings. On the other hand, it has been found in this study that external homogeneous electrostatic field could have significant influence on the $\mathrm{HOH}$ bending frequencies. If the electric field was directed parallel to the water molecule dipole moment (i.e. parallel to the $z$-axis coinciding with the $C_{2}$ axis) a very small $\delta(\mathrm{HOH})$ frequency upshift (blue-shift) has been found. On the other hand, when the field is directed oppositely to the water dipole moment vector, then the frequency exhibited a remarkable downshift (red-shift). For example, a field with magnitude of 0.060 a.u. applied parallel to the water dipole leads to frequency upshift of about only $10 \mathrm{~cm}^{-1}$ with respect to the value for free water. A field of the same magnitude, but oriented antiparallel to the water dipole moment, would lead to frequency downshift with appreciable magnitude of approximately $200 \mathrm{~cm}^{-1}$. Downshift of the order of $100 \mathrm{~cm}^{-1}$ has been obtained for field strengths of about 0.030 a.u. These findings opened the possibility that the frequency of the $\mathrm{HOH}$ bending mode could exhibit red shift as a consequence of vibrational Stark effect (under an assumption that the crystalline field is "properly" oriented), i.e. that the observed spectral features could be due to longrange electrostatics effects; of course, all this pro- vided that the results obtained with explicit inclusion of the in-crystal neighbors are correct. Interestingly enough, however, contrary to the HF SCF level of theory, the PM3 results gave qualitatively correct trends even upon inclusion of the first-order in-crystal neighbors of the crystalline water molecules. However, since the description of $\mathrm{Mg}^{2+}$ and $\mathrm{K}^{+}$ions by the PM3 Hamiltonian is hardly much different form point charges, it is possible that PM3 level of theory actually also predicts electrostatically-induced red shift of the $\delta(\mathrm{HOH})$ mode. Perhaps the only exact and unequivocal conclusion that could be derived from the outlined theoretical approaches was that the frequency shift is due to the $\delta(\mathrm{HOH})$ mode to lower frequencies could appear due to "flattening" of the $\delta(\mathrm{HOH})$ vibrational potential, i.e. due to changes of the harmonic force constant. In contrast, the anharmonic contributions to the overall shift have been found to be negligible in [42].

All in all, having in mind the rather modest level of theory implemented in these initial theoretical attempts to solve the problem in question, one cannot guarantee the sufficiency of the implemented theoretical level for the mentioned purposes. For these reasons, more elaborate theoretical studies have been undertaken recently after publication of [42] in order to address the problem in a more thorough manner. These further studies [43-45] have been based on combined application of HF as well as Density functional theory approach (DFT), based on combination of Becke's three-parameter adiabatic connection exchange functional [58] with the Lee-Yang-Parr [59] correlation functional (usually denoted with the acronym B3-LYP). The modest size, but still sufficient in the sense of providing convergency of the results, 6$31++\mathrm{G}(d, p)$ basis set has been used for orbital expansion in the course of seeking iteratively for the solutions of the HF or Kohn-Sham (KS) equations. In this study, the problem of explicit inclusion of the in-crystal environment of the water molecule has been addressed in a much more systematic manner. Thus, several finite clusters that have been aimed to represent, i.e. mimick the crystalline surrounding of the vibrating water molecule have now been considered (Fig. 4). The first one was the $\mathrm{Mg}^{2+} \mathrm{K}^{+}\left(\mathrm{H}_{2} \mathrm{O}\right)$ cluster, which includes only the nearestneighboring metal cations. The second one, aside from the closest cationic species, also included the nearest phosphate anions as well, i.e. is of the form $\mathrm{Mg}^{2+} \mathrm{K}^{+}\left(\mathrm{PO}_{4}{ }^{3-}\right)_{2}\left(\mathrm{H}_{2} \mathrm{O}\right)$, while the largest cluster involved the second neighboring phosphate anions as well: $\mathrm{Mg}^{2+} \mathrm{K}^{+}\left(\mathrm{PO}_{4}{ }^{3-}\right)_{4}\left(\mathrm{H}_{2} \mathrm{O}\right)$. To discriminate between the purely electrostatic effects and the influence of short-range intermolecular interactions, also the "charge-field" analogues of the previously de- 
scribed clusters have been considered. These "chargefield" clusters have been constructed simply by exchanging the ionic species with the point charges of the corresponding magnitude placed at the corresponding centers of mass of the realistic species.

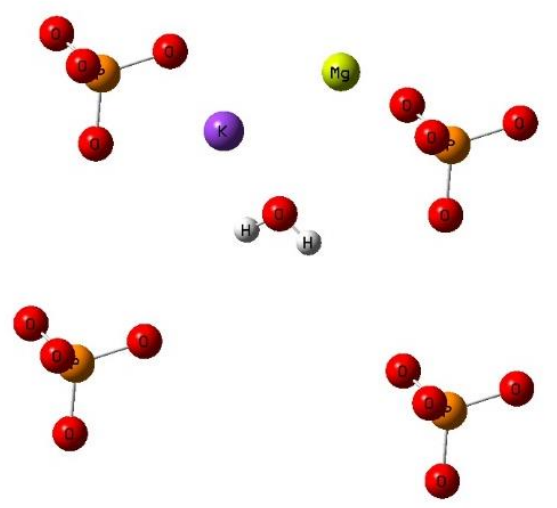

a)

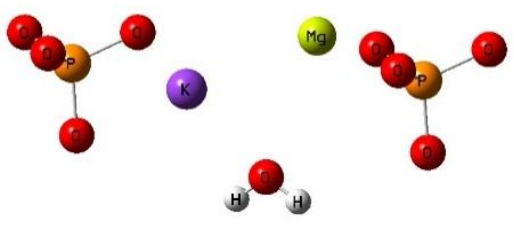

b)

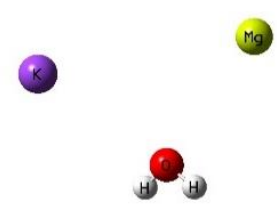

c)

Figure 4. A schematic presentation of the finite clusters used to model the $\delta(\mathrm{HOH})$ frequencies in the studied series of compounds: a) $\mathrm{Mg}^{2+} \mathrm{K}^{+}\left(\mathrm{PO}_{4}{ }^{3-}\right)_{4}\left(\mathrm{H}_{2} \mathrm{O}\right)$, b) $\mathrm{Mg}^{2+} \mathrm{K}^{+}\left(\mathrm{PO}_{4}{ }^{3-}\right)_{2}\left(\mathrm{H}_{2} \mathrm{O}\right)$, c) $\mathrm{Mg}^{2+} \mathrm{K}^{+}\left(\mathrm{H}_{2} \mathrm{O}\right)$.

Such charge field perturbational-like (CFP) approach for modeling the electrostatic + polarization influence on the $\delta(\mathrm{HOH})$ vibrational frequencies accounts completely for all terms in the perturbation-theory expansion of the energy as a function of the field:

$$
\begin{aligned}
& -\Delta E(\vec{F})=\vec{\mu}^{0} \cdot \vec{F}+\frac{1}{2 !} \bar{\Theta} \cdot \nabla \vec{F}+\frac{1}{3 !} \bar{\Omega} \cdot \nabla^{2} \vec{F}+ \\
& +\frac{1}{4 !} \bar{\Phi} \cdot \nabla^{3} \vec{F}+\cdots+\frac{1}{2 !} \bar{\alpha} \cdot \vec{F}^{+}+\cdots
\end{aligned}
$$

In the previous equation, $\bar{\Theta}, \bar{\Omega}, \bar{\Phi}, \ldots$ are the quadrupole, octupole, hexadecapole tensor functions of second, third, fourth etc. order, while $\vec{\mu}^{0}$ and $\bar{\alpha}$ are the dipole moment vector of the free molecule and the dipole polarizability function, respectively. The last quantity is actually a second order tensor.

The geometry of the "in-crystal" water molecule embedded within the mentioned clusters has been fully optimized at the mentioned levels of theory. Subsequently, the $\delta(\mathrm{HOH})$ vibrational frequency has been computed by diagonalization of the mass-weighted Hessian matrix computed for the minima on the corresponding potential energy hypersurfaces (PESs). Adopting the doubleharmonic approximation as a method of choice for the currently studied system has been fully justified by the previously mentioned preliminary-like results $[41,42]$ in which we have demonstrated that the contribution of anharmonicity to the overall trends and even to absolute frequency values when the $\delta(\mathrm{HOH})$ mode is in question are indeed minor ones.

Inclusion of only the nearest $\mathrm{Mg}^{2+}$ and $\mathrm{K}^{+}$ ions to the vibrating in-crystal water molecule, practically regardless on the implemented level of theory have led to a $\delta(\mathrm{HOH})$ frequency upshift (blue-shift) of approximately $70 \mathrm{~cm}^{-1}$ (with respect to the free water value). One can therefore safely conclude that interaction with these two ionic species that reside in the immediate vicinity of the crystalline water in $\mathrm{MgKPO}_{4} \cdot \mathrm{H}_{2} \mathrm{O}$ can not be regarded as being responsible for the observed significant frequency downshift (red-shift). Moreover, it has been further shown in [43-45] that purely electrostatic interaction with these two ions (as computed by the charge field perturbational approach) would lead to only a small frequency upshift, contrary to the full-wavefunction value (less than about $26 \%$ regardless on the employed theoretical level). This observation would certainly not be expected if one is led by a purely "chemical" reasoning. It has been, however, argued in $[44,45]$ that the exchange component of the interaction energy (i.e. the "Pauli repulsion" term) could be regarded as responsible for such trend. Further addition of two nearestneighboring phosphate ions to the initial $\mathrm{Mg}^{2+} \mathrm{K}^{+}\left(\mathrm{H}_{2} \mathrm{O}\right)$ cluster (i.e. building it up further to the $\left.\mathrm{Mg}^{2+} \mathrm{K}^{+}\left(\mathrm{PO}_{4}{ }^{3-}\right)_{2}\left(\mathrm{H}_{2} \mathrm{O}\right)\right)$ readily leads to a significant flattening of the $\delta(\mathrm{HOH})$ potential, and, consequently, a too large frequency red shift (as large as $350 \mathrm{~cm}^{-1}$ ). It could be concluded that placement of phosphate ions on the oxygen side of crystalline water molecule ("above" the hydrogen atoms) imposes a strong influence on its deformation mode, 
resulting in drastic reduction of its harmonic force constant. Within the framework of the NBO theory, one would actually expect significant charge transfer (CT) interaction occurring e.g. from $\mathrm{PO}_{4}{ }^{3-}$ nonbonding states to the $\mathrm{OH}$ antibonding ones. As shown by the CFP analysis of this cluster, the purely electrostatic interaction between the crystalline water molecule and its neighbors in the described cluster would cause an even larger flattening of the $\delta(\mathrm{HOH})$ vibrational potential. The CT term, thus, most probably counteracts the classical electrostatics with this respect. Finally, expanding further the $\mathrm{Mg}^{2+} \mathrm{K}^{+}\left(\mathrm{PO}_{4}{ }^{3-}\right)_{2}\left(\mathrm{H}_{2} \mathrm{O}\right)$ cluster with additional two phosphate ions placed "below" water hydrogen atoms (i.e. building up the $\mathrm{Mg}^{2+} \mathrm{K}^{+}\left(\mathrm{PO}_{4}{ }^{3-}\right)_{4}\left(\mathrm{H}_{2} \mathrm{O}\right)$ cluster) seems to nicely balance everything at $\mathrm{HF}$ level of theory, leading to an overall frequency redshift of about $150 \mathrm{~cm}^{-1}$, in good agreement with the experimental data. B3LYP shift was, however, shown to be significantly smaller $\left(\sim 26 \mathrm{~cm}^{-1}\right)$. All in all, if one analyzes the dependence of $\delta(\mathrm{HOH})$ frequencies on the equilibrium values of the $\mathrm{HOH}$ angle, a very good correlation between the later two quantities. To get a further insight into the direction and magnitude of the charge transfer interactions (CT) within the studied clusters, NBO analyses have been carried out in [43-45]. More precisely, second-order perturbation theory analysis of the Fock matrix (or its Kohn-Sham analogue) within the NBO basis had actually been carried out in [45], at HF level of theory. The energetic effects due to these interactions have been estimated by the second-order perturbation theoretical (SOPT) expressions of the form [60]:

$$
\Delta E_{\psi \text { donor } \rightarrow \psi \text { acceptor }}^{(2)} \approx-2 \cdot \frac{\left\langle\psi_{\text {don }}^{*}|\hat{F}| \psi_{\text {acc }}\right\rangle^{2}}{\varepsilon_{\text {acc }}-\varepsilon_{\text {don }}}
$$

In (4), $\varepsilon_{\mathrm{i}}$ is a diagonal NBO matrix element of the Fock operator $\hat{F}$ (or, in the case of the DFT formalism, the Kohn-Sham one-electron analog $\left.\hat{h}_{\mathrm{KS}}\right)$. The quantities of transferred charge from a given donor to a given acceptor orbital have been, on the other hand, estimated using elementary perturbation theory arguments. The following approximate formula has been obtained on the basis of SOPT treatment [60]:

$$
q_{\psi \text { donor } \rightarrow \psi \text { acceptor }} \approx 2\left(\frac{\left\langle\psi_{\text {don }}^{*}|\hat{F}| \psi_{\text {acc }}\right\rangle}{\varepsilon_{\text {acc }}-\varepsilon_{\text {don }}}\right)^{2}
$$

It has been found out that the most significant CT occurs in the direction from water oxygen atom nonbonding orbital to the extra-valence (Rydberg) states of the $\mathrm{Mg}^{2+}$ ion. This particular interorbital interaction appeared to be the strongest CT interaction within the cluster. In this manner, the differences between full-wavefunction and CFP results related to the $\delta(\mathrm{HOH})$ frequency shifts in the case of smallest clusters considered, becomes clearly understandable. Considering the water $\rightarrow \mathrm{K}^{+} \mathrm{CT}$ interaction, it has been shown to be negligibly small, i.e. one could safely state that no significant $\mathrm{CT}$ has been found to occur between water oxygen nonbonding states to the potassium ion virtual states. CT in the direction phosphate $\rightarrow$ water has been found to be essentially unidirectional. Most of it occurs from the nonbonding orbitals of the phosphate ions oxygen atoms to the water molecule $\mathrm{O}-$ $\mathrm{H}$ antibonding states. All of the four phosphate ions appeared to be equivalent in the sense of CT interaction with the "central" water molecule. It is also worth noting that though the overall charge transfer has been found to be small on an absolute scale, it is still rather significant in a chemical sense.

\section{CONCLUSIONS}

One of the classical paradigms related to spectroscopy of crystalline water in solid state hydrates has been related to the spectral area of appearance of the water bending mode; this mode has been expected to give rise to bands at frequency values that are higher (blue-shifted) or only slightly lower (i.e. red-shifted) as compared to the freewater value. In the early works of academician Šoptrajanov and his group and collaborators, however, this paradigm has been questioned and further on confirmed not to be true in a general case. Subsequent developments in the field have further propelled this idea, expanded the knowledge of systems in which this apparent "unusual" behavior has been experimentally detected, and also enabled certain theoretical insights to be gained. All these aspects have been overviewed in this topical review, following the temporal development of ides, as well as the conceptual methodological development. Our current level of fundamental understanding of the phenomenon itself has been considered in detail, carefully pinpointing the weak sides and the possibilities for further developments. On the basis of currently available experimental and theoretical data, the following general conclusions related to the phenomenon may be outlined:

- Carefully collected experimental data for protiated and deuterated samples of $\mathrm{MKPO}_{4} \cdot \mathrm{H}_{2} \mathrm{O}$, where 
$\mathrm{M} \in\{\mathrm{Ni}, \mathrm{Mg}, \mathrm{Co}, \mathrm{Mn}\}$, as well as $\mathrm{MNH}_{4} \mathrm{PO}_{4} \cdot \mathrm{H}_{2} \mathrm{O}$ (where $\mathrm{M} \in\{\mathrm{Mg}, \mathrm{Co}, \mathrm{Ni}, \mathrm{Mn}, \mathrm{Cd}\}$ ) have unambiguously implied the existence of "low-bending crystalline water modes", i.e. bands due to water scissoring mode appearing at significantly lower frequencies than even the lowest "Falk's" limit reported before.

- Low frequencies of the $\mathrm{HOH}$ bending mode in crystalline water molecules may be in principle induced if the effective local crystalline field vector at the in-crystal water site is directed oppositely to the water dipole moment vector.

- Homogeneous field with magnitude of 0.060 a.u. applied parallel to the water dipole leads to frequency upshift of about only $10 \mathrm{~cm}^{-1}$ with respect to the value for free water, while a field of the same magnitude, oriented antiparallel to the water dipole moment, would lead to frequency downshift with appreciable magnitude of approximately 200 $\mathrm{cm}^{-1}$. Downshift of the order of $100 \mathrm{~cm}^{-1}$ could be obtained for field strengths of about 0.030 a.u.

- More explicit inclusion of the in-crystal neighborhood around the "peculiar" water molecules enables more light to be shed on the reasons behind the appearance of low-lying $\delta(\mathrm{HOH})$ modes.

- The nearest-neighboring phosphate groups around the crystalline water are positioned such that a notable "flattening" of the $\delta(\mathrm{HOH})$ vibrational potential occurs, manifested as a significant reduction in the harmonic force constant value. The effect is much more pronounced if only the $\mathrm{PO}_{4}{ }^{3-}$ groups lying above the water are accounted for; those placed below in part counteract it and make a suitable balance in the overall $\delta(\mathrm{HOH})$ mode.

- Anharmonic contributions to this shift were found to be of minor importance whatsoever.

Despite the outlined points, one could not say that the story of low-bending crystalline water molecules ends here. This is mostly due to the fact that the crystalline structure of most compounds in which this effect is manifested are yet unknown in details. At the same time, more rigorous periodic DFT computations could be applied to the problem, where all of the crystalline environment would be integrally accounted for. If combined with the finite-cluster approach, such studies could certainly shed much more light into each of the individual contributions to the overall experimentally observed shift of this mode. Such preliminary studies are actually in progress. Of course, last but not least, if more experimental spectroscopic data become available, much more and also finer details of the trends encountered in a series of structurally similar or distinct compounds could be involved in the forthcoming analyses.

\section{REFERENCES}

[1] P. Jungwirth, Biological water or rather water in biology?, J. Phys. Chem. Lett., 6 (2015), pp. 24492451.

[2] D. Zhong, S. K. Pal, A. H. Zewail, Biological water: A critique, Chem. Phys. Lett., 503 (2011), pp. $1-11$.

[3] F. Despa, Biological water: Its vital role in macromolecular structure and function., Ann. N. Y. Acad. Sci., 1066 (2005), pp. 1-11.

[4] Y. Gao, B. Xu, Probing thermal conductivity of fullerene $\mathrm{C}_{60}$ hosting a single water molecule, $J$. Phys. Chem. C, 119 (2015), pp. 20466-20473.

[5] K. Kurotobi, Y. Murata, A single molecule of water encapsulated in fullerene $\mathrm{C}_{60}$, Science, $\mathbf{3 3 3}$ (2011), pp. 613-616.

[6] A. B. Farimani, Y. Wu, N. R. Aluru, Rotational motion of a single water molecule in a buckyball, Phys. Chem. Chem. Phys., 15 (2013), pp. 1799318000.

[7] B. Meier, S. Mamone, M. Concistre, J. AlonsoValdesueiro, A. Krachmalnicoff, R. J. Whitby, M. H. Levitt, Electrical detection of ortho-para conversion in fullerene-encapsulated water, Nature Comm., 6 (2015), pp. 8112-8115.

[8] S. Mamone, M. Concistre, E. Carignani, B. Meier, A. Krachmalnicoff, O. G. Johannessen, X. Lei, Y. Li, M. Denning, M. Carravetta, K. Goh, A. J. Horsewill, R. J. Whitby, M. H. Levitt, Nuclear spin conversion of water inside fullerene cages detected by low-temperature nuclear magnetic resonance, J. Chem. Phys., 140 (2014), 194306 (pp. 112).

[9] B. Xu, X. Chen, Electrical-driven transport of endohedral fullerene encapsulating a single water molecule, Phys. Rev. Lett., 110 (2013) 156103 (pp. $1-5)$.

[10] D. Marx, A. Chandra, M. E. Tuckerman, Aqueous basic solutions: Hydroxide solvation, structural diffusion, and comparison to the hydrated proton, Chem. Rev., 110 (2010), pp. 2174-2216.

[11] P. B. Petersen, R. J. Saykally, Is the liquid water surface basic or acidic? Macroscopic vs. molecular-scale investigations, Chem. Phys. Lett., 458 (2008), pp. 255-261.

[12] B. Winter, M. Faubel, R. Vácha, P. Jungwirth, Behavior of hydroxide at the water/vapor interface, Chem. Phys. Lett., 474 (2009), pp. 241-247.

[13] C. J. Mundy, I-F. W. Kuo, M.E. Tuckerman, H-S Lee, D. J. Tobias, Hydroxide anion at the air-water interface, Chem. Phys. Lett., 481 (2009), pp. 2-8.

[14] N. Agmon, Mechanism of hydroxide mobility, Chem. Phys. Lett., 319 (2000), pp. 247-252. 
[15] M. E. Tuckerman, A. Chandra, D. Marx, Structure and dynamics of $\mathrm{OH}^{-}(\mathrm{aq})$, Acc. Chem. Res., 39 (2006), pp. 151-158.

[16] M. A. Tuckerman, D. Marx, M. Parrinello, The nature and transport mechanism of hydrated hydroxide ions in aqueous solution, Nature, 417 (2002), pp. 925-929.

[17] K. Hermansson, Ph. A. Bopp, D. Spångberg, Lj. Pejov, I. Bakò, P. D. Mitev, The vibrating hydroxide ion in water, Chem. Phys. Lett., 514 (2011), pp. $1-15$.

[18] M. F. C. Ladd, W. H. Lee, Crystalline hydrates. II, J. Phys. Chem., 73 (1969), pp. 2033-2035.

[19] M. F. C. Ladd, W. H. Lee, The thermodynamics of crystalline hydrates, J. Phys. Chem., 69 (1965), pp. 1840-1843.

[20] K. Hermansson, Ab initio calculations of the fundamental $\mathrm{OH}$ frequency of bound $\mathrm{OH}^{-}$ions, $J$. Chem. Phys., 95 (1991), pp. 3578-3588.

[21] K. Hermansson, Electric-field effects on the $\mathrm{OH}$ vibrational frequency and infrared absorption intensity for water, J. Chem. Phys., 99 (1993), pp. 861-886.

[22] J-H. Choi, M. Cho, Computational IR spectroscopy of water: $\mathrm{OH}$ stretch frequencies, transition dipoles, and intermolecular vibrational coupling constants, J. Chem. Phys., 138 (2013), 174108 (pp. 1-18).

[23] K. Hermansson, $\mathrm{O}-\mathrm{H}$ bonds in electric fields: electron densities and vibrational frequency shifts, Chem. Phys. Lett. 233 (1995), pp. 376-382.

[24] K. Hermansson, H. Tepper, Electric field effects on vibrating polar molecules from weak to strong fields, Mol. Phys., 89 (1996), pp. 1291-1299.

[25] B. Berglund, J. Lindgren, J. Tegenfeldt, O-H and O-D stretching vibrations in isotopically dilute HDO molecules in some solid hydrates, J. Mol. Struct., 43 (1978), pp. 169-177.

[26] W. Mikenda, Stretching frequency versus bond distance correlation of $\mathrm{O}-\mathrm{D}(\mathrm{H}) \cdots \mathrm{Y}(\mathrm{Y}=\mathrm{N}, \mathrm{O}, \mathrm{S}$, $\mathrm{Se}, \mathrm{Cl}, \mathrm{Br}, \mathrm{I})$ hydrogen bonds in solid hydrates, $J$. Mol. Struct., 147 (1986), pp. 1-15.

[27] A. Novak, Hydrogen bonding in solids correlation of spectroscopic and crystallographic data, Struct. Bond., 18 (1974), pp. 177-216.

[28] M. Falk, The frequency of the H-O-H bending fundamental in solids and liquids, Spectrochim. Acta A, 40 (1984), pp. 43-48.

[29] H. D. Lutz, Bonding and structure of water molecules in solid hydrates. Correlation of spectroscopic and structural data, Struct. Bond., 69 (1988), pp. 97-125.

[30] W. S. Benedict, N. Gailar, E. K. Plyler, Rotationvibration spectra of deuterated water vapor, $J$. Chem. Phys., 24 (1956), pp. 1139-1165.
[31] M. Gailar, F. P. Dickey, The vibration-rotation band $v_{2}$ of HDO vapor, J. Mol. Spectrosc., 4 (1964), pp. 1-15.

[32] C. Furlani, Gazz. Chim. Ital., 88 (1958), p. 65.

[33] G. Sartori, C. Furlani, A. Damiani, On the problem of the vibrational frequencies of water in complexes, J. Inorg. Nucl. Chem., 8 (1958), pp. 119-125.

[34] J. Sadlej, A. J. Sadlej, Theoretical infrared and Raman spectroscopic parameters for $\mathrm{H}_{2} \mathrm{O}$ and the $\mathrm{H}_{2} \mathrm{O} \cdots \mathrm{Li}^{+}$system, J. Chem. Soc., Faraday Disccuss., 64 (1977), pp. 112-119.

[35] K. Hermansson, I. Olovsson, S. Lunnell, Cation influence on the structure and electron density of water in some $\mathrm{Me}^{\mathrm{n}+} \cdot \mathrm{H}_{2} \mathrm{O}$ complexes, Theor. Chim. Acta, 64 (1984), pp. 265-276.

[36] M. Falk, H. T. Flakus, R. J. Boyd, An ab initio SCF calculation of the effect of water-anion and water-cation interactions on the vibrational frequencies of water, Spectrochim. Acta A, 42 (1986), pp. 175-180.

[37] B. Šoptrajanov, Fac. Sci., Univ. Kiril et Metodij, Skopje, Editions Speciales, Livre 16, Skopje, 1973.

[38] B. Šoptrajanov, Very low $\mathrm{H}-\mathrm{O}-\mathrm{H}$ bending frequencies in the infrared spectra of some crystallohydrates, XXVI Colloquium Spectroscopicum Internationale, Sofia, Vol. V (1989), pp. 71-80.

[39] M. Trpkovska, B. Šoptrajanov, Infrared spectra of $\mathrm{Cu}(\mathrm{II})$ sulfate monohydrate, XXVI Colloquium Spectroscopicum Internationale, Sofia, Vol. II (1989), p. 167.

[40] A. Grodzicki, P. Piszczek, A new interpretation of abnormal shift of water molecules' bending vibration frequencies in kieserite family monohydrates, J. Mol. Struct., 443 (1998), pp. 141-147.

[41] B. Šoptrajanov, Very low $\mathrm{H}-\mathrm{O}-\mathrm{H}$ bending frequencies. I. Overview and infrared spectra of $\mathrm{NiKPO}_{4} \cdot \mathrm{H}_{2} \mathrm{O}$ and its deuterated analogues, J. Mol. Struct., 555 (2000), pp. 21-30.

[42] Lj. Pejov, B. Šoptrajanov, G. Jovanovski, Very low $\mathrm{H}-\mathrm{O}-\mathrm{H}$ bending frequencies. II. Quantum chemical study of the water bending potential in compounds of the $\mathrm{MKPO}_{4} \cdot \mathrm{H}_{2} \mathrm{O}$ type, J. Mol. Struct., 563-564 (2001), pp. 321-327.

[43] B. Šoptrajanov, G. Jovanovski, Lj. Pejov, Very low $\mathrm{H}-\mathrm{O}-\mathrm{H}$ bending frequencies. III. Fourier transform infrared study of cobalt potassium phosphate monohydrate and manganese potassium phosphate monohydrate, J. Mol. Struct., 613 (2002), pp. 47-54.

[44] B. Šoptrajanov, V. Stefov, I. Kuzmanovski, G. Jovanovski, H. D. Lutz, B. Engelen, Very low H$\mathrm{O}-\mathrm{H}$ bending frequencies. IV. Fourier transform infrared spectra of synthetic dittmarite, J. Mol. Struct., 613 (2002), pp. 7-14. 
[45] B. Šoptrajanov, Lj. Pejov, G. Jovanovski, V. Stefov, Very low $\mathrm{HOH}$ bending vibrations. V. Quantum chemical study of water bending vibrations in $\mathrm{MgKPO}_{4} \cdot \mathrm{H}_{2} \mathrm{O}$, J. Mol. Struct., 706 (2004), pp. 101-106.

[46] GRAMS32 for Microsoft Windows, Ver. 4.10, Galactic Industries Corp., 1991-1996.

[47] R. Kevorkyants, A. V. Rudakova, Y. V. Chizov, K. M. Bulanin, The origin of $1560 \mathrm{~cm}^{-1}$ band in experimental IR spectra of water adsorbed on $\mathrm{TiO}_{2}$ surface: Ab initio assessment, Chem. Phys. Lett., 662 (2016), pp. 97-101.

[48] Lj. Pejov, M. Ristova, Z. Zdravkovski, B. Šoptrajanov, $A b$ initio quantum chemical and experimental study of structure, harmonic vibrational frequencies and internal $\mathrm{Ph}-\mathrm{SO}_{3}$ torsion of benzenesulfonate anion, J. Mol. Struct., 524 (2000), pp. 179-188.

[49] Lj. Pejov, M. Ristova, B. Šoptrajanov, A gradientcorrected density functional study of structure, harmonic vibrational frequencies and charge distribution of benzenesulfonate anion on the groundstate potential energy surface, J. Mol. Struct., 555 (2000), pp. 341-349.

[50] F. Weinhold and J. E. Carpenter, in: The Structure of Small Molecules and Ions, Ed. R. Naaman and Z. Vager (Plenum, 1988), pp. 227-236.

[51] J. Fraissard, J. J. Étienne, Bull. Soc. Fr. Mineral. Cristallogr., 90 (1967), p. 162.
[52] G. Jovanovski, S. Pocev, B. Kaitner, Crystal structure of magnesium potassium phosphate monohydrate $\left(\mathrm{MgKPO}_{4} \cdot \mathrm{H}_{2} \mathrm{O}\right)$, Bull. Chem. Technol. Macedonia, 16 (1997), pp. 59-63.

[53] T. H. Dunning Jr. and P. J. Hay, in Modern Theoretical Chemistry, Ed. H. F. Schaefer III, Vol. 3 (Plenum, New York, 1977), pp. 1-28.

[54] P. J. Hay, W. R. Wadt, Ab initio effective core potentials for molecular calculations - potentials for the transition-metal atoms Sc to $\mathrm{Hg}, J$. Chem. Phys., 82 (1985), pp. 270-283.

[55] H. B. Schlegel, Optimization of Equilibrium Geometries and Transition Structures, J. Comp. Chem., 3 (1982), pp. 214-218.

[56] R. F. W. Bader, Atoms in Molecules - A Quantum Theory, Oxford University Press, Oxford, 1990.

[57] M. J. Frisch et al, Gaussian 03, Revision C.02, Gaussian, Inc. Wallingford CT, 2004.

[58] A. D. Becke, Density-functional exchange-energy approximation with correct asymptotic behavior, Phys. Rev. A, 38 (1988), pp. 3098-3100.

[59] C. Lee, W. Yang, R. G. Parr, Development of the Colle-Salvetti correlation-energy formula into a functional of the electron density, Phys. Rev. B, 37 (1988), pp. 785-789.

[60] A. E. Reed, L. A. Curtiss, F. Weinhold, Intermolecular interactions from a natural bond orbital, donor-acceptor viewpoint, Chem. Rev., 88 (1988) pp. 899-926.

\title{
НИСКИ ДЕФОРМАЦИОНИ ВИБРАЦИИ НА КРИСТАЛНИ МОЛЕКУЛИ ВОДА: ТЕКОВНО ТРАГАЊЕ ИЛИ КОНЕЧЕН ЗБОР - ТЕМАТСКИ ПРЕГЛЕДЕН ТРУ Д - ОМАЖ ЗА АКАДЕМИК БОЈАН ШОПТРАЈАНОВ -
}

\author{
Љупчо Пејов, Глигор Јовановски
}

\begin{abstract}
Институт за хемија, Природно-математички факултет, Универзитет „Св. Кирил и Методиј”, Скопје, Република Македонија

Истражувачки центар за животна средина и материјали, Македонска академија на науките и уметностите, Скопје, Република Македонија
\end{abstract}

Целта е, во овој тематски прегледен труд, да се даде концизен и комплетен преглед на извршените истражувања од областа на ниските деформациони вибрации на кристалните молекули на водата. Направен е преглед на досега добиените теоретски и експериментални резултати на ова поле, со посветување на посебно внимание на појавените најважни дилеми и пречки кои го оневозможуваат директното објаснување на забележаниот феномен. Направен е, исто така, обид да се разјаснат моменталните состојби на ова поле на истражување. Иако во овој преглед главниот акцент е фокусиран на кристалните молекули вода кај кристалохидратите, како и на нивните вибрациони својства, посочени се, исто така, и некои други интересни системи кои неодамна го привлекоа вниманието на научната јавност. Тие вклучуваат вода апсорбирана на површините како и на меѓуповршините воздух-вода.

Клучни зборови: кристална вода; кристалохидрати; деформациони вибрации на водата; ИЦ спектроскопија; квантна теорија 